\title{
Performance Evaluation of Next Generation Networks using OPNET Simulator
}

\author{
Ritesh Sadiwala \\ Ph.D. Research Scholar \\ Department of Electronics \&Communication Engg \\ RKDF University, Bhopal, M.P., India
}

\author{
Minal Saxena, PhD \\ Professor \& Dean \\ Electronics \& Communication Engg. Department \\ SIRT, Bhopal, M.P., India
}

\begin{abstract}
In telecommunication, traditionally telephone networks uses basic concept called circuit switching for doing communication between sender and receiver such as Public Switched Telephone Network (PSTN). Nowadays this type of switching is being replaced by packet switching where the transmission of data is done in packets and networks based on this are referred to as connectionless networks. Voice over Internet Protocol (VOIP) is an emerging technology which is based on packet switching and is going to be used for the transmission of voice and multimedia over the Internet Protocol (IP) based network, especially the Internet. Another is WiMAX Technology which is also an upcoming wireless technology that provides us high speed mobile data and telecommunication services. These technologies are in use to replace the traditional telephone networks i.e., Public Switched Telephone Network (PSTN). In this paper performance of such networks which uses VOIP technology is investigated and for which OPNET 14.5 Simulator is chosen as the platform. OPNET Simulator provides simulated reallife environment, in order to study the performance of the next generation networks. The parameters used to evaluate the performance of the networks are jitter and end to end delay. Finally based on the simulations best VOIP codec is also found out.
\end{abstract}

\section{Keywords}

VOIP Codecs, OPNET, QOS, VOIP, PSTN

\section{INTRODUCTION}

A Telecommunication protocol such as Worldwide Interoperability for Microwave Access (WiMAX) provides wireless Internet access for fixed and mobile nodes. It is based on IEEE 802.16 wireless Metropolitan Area Network standard and has been deployed extensively in recent years to solve the problems associated with point-to-multipoint broadband outdoor wireless networks [1]. There are two types of Wimax which are used for different applications and the implementation of each has been optimized to suit particular application. Voice over IP over Wimax, is the best application in IEEE 802.16e which aims at providing multimedia Application services [2], [3]. As NGN networks are all-IP networks, voice service over NGN are implemented as Voice over IP (VoIP). The data rate generated by VoIP codecs differs from one codec to another as there is a tradeoff between the voice quality, generated date rate and complexity of codec [4]. In this paper the performance of VoIP QOS in NGN networks like WIMAX will be investigated, by using some VoIP codec according to standard of International Telecommunication Union (ITU). The rest of this paper is organized as follows. Section II describes the QOS in IEEE 806, VoIP and VoIP codecs. Section III provides the model design and configuration networks. Results are given in Section IV. Finally, section V concludes the paper.

\section{LITERATURE REVIEW}

In this section description of VOIP, VOIP codecs and QOS parameters are discussed.

\subsection{Quality of Service (QOS) in NGN Networks}

Quality of Service (QOS) is what determines if a wireless technology can successfully deliver high value services such as voice and video. To support the different types of traffic with their various requirements IEEE 802.16 defines five QOS service classes: Unsolicited Grant Scheme (UGS), Extended Real Time Polling Service (ertPS), and Real Time Polling Service (rtPS), Non Real Time Polling Service (nrtPS) and Best Effort Service (BE). Fixed WiMAX offers 4 categories for the prioritization of traffic and mobile WiMAX has 5 categories. These categories are given in Table 1.

Table 1: QOS Service Classes

\begin{tabular}{|c|c|c|}
\hline $\begin{array}{c}\text { Service } \\
\text { Class }\end{array}$ & Applications & $\begin{array}{c}\text { QOS } \\
\text { Specifications }\end{array}$ \\
\hline $\begin{array}{l}\text { Unsolicited } \\
\text { Grant Service } \\
\text { (UGS) }\end{array}$ & VoIP & $\begin{array}{c}\text { - Jitter tolerance } \\
\text { - Maximum } \\
\text { latency tolerance } \\
\text { - Maximum } \\
\text { sustained rate }\end{array}$ \\
\hline $\begin{array}{l}\text { Real-time Packet } \\
\text { Services (RTPS) }\end{array}$ & $\begin{array}{c}\text { Streaming } \\
\text { Audio/Video }\end{array}$ & $\begin{array}{c}\text { - Traffic priority } \\
\text { - Maximum } \\
\text { latency tolerance } \\
\text { - Maximum } \\
\text { reserved rate } \\
\text { - Maximum } \\
\text { sustained rate }\end{array}$ \\
\hline $\begin{array}{l}\text { Extended real time } \\
\text { Packet Services } \\
\text { (ERTPS) }\end{array}$ & $\begin{array}{l}\text { VoIP (VoIP with } \\
\text { Activity } \\
\text { Detection) }\end{array}$ & $\begin{array}{l}\text { - Traffic priority } \\
\text { - Jitter tolerance } \\
\text { - Maximum } \\
\text { latency tolerance } \\
\text { - Maximum }\end{array}$ \\
\hline
\end{tabular}




\begin{tabular}{|c|c|c|}
\hline & & $\begin{array}{c}\text { reserved rate } \\
\text { - Maximum } \\
\text { sustained rate }\end{array}$ \\
\hline $\begin{array}{c}\text { Non-real } \\
\text { time } \\
\text { Packet } \\
\text { Services } \\
\text { (NRTPS) }\end{array}$ & FTP & - Traffic priority \\
& & - Maximum \\
& & reserved rate \\
& & - Maximum \\
& & sustained rate \\
\hline Best Effort (BE) & Data transfer, & - Traffic priority \\
& web browsing & - Maximum \\
& & sustained rate \\
& & \\
\hline
\end{tabular}

\subsection{Voice Over IP}

Voice is analog in nature and is converted into the digital format before transmitting it over Internet. This process is called encoding and the reverse is called decoding. Both the tasks are performed by voice codecs [5]. As bandwidth utilization is becoming a great concern, voice compression techniques are used in practice to reduce the bandwidth consumption. VoIP, or Voice over Internet Protocol, is a method for taking analog audio signals and turning them into digital data that can be transmitted over the Internet. VoIP uses a combination of protocols for delivering the phone data over networks. Various signaling protocols are used, SIP and H.323 can be regarded as the enabler protocols for voice over IP (VoIP) services [6]. VoIP communications require these signaling systems to setup, control, initiate a session and facilitate real-time data transfer in order to provide clear communications [7].

\subsection{VoIP Codecs}

The CODEC (Coder/Decoder) is the component in an IP phone that digitizes the voice and converts it back into an analog stream of speech. The CODEC is the analog-to-digital and digital-to-analog converter. The CODEC may also perform the voice compression and decompression. There are several voice digitization standards and from that some proprietary techniques are in use for VoIP transmission. Here some generally used codecs are discussed.

- G.711 is a codec that was introduced by ITU in 1972 for use in digital telephony, i.e. in ISDN, T.1 and E.1 links. The codec has two variants: A-Law and u-Law. A-Law is being used in Europe and in international telephone links, u-Law is used in the U.S.A. and Japan. G.711 uses a logarithmic compression. It squeezes each 16-bit sample to 8 bits, thus it achieves a compression ratio of 1:2. The resulting bitrate is $64 \mathrm{Kbit} / \mathrm{s}$ for one direction, so a call consumes $128 \mathrm{Kbit} / \mathrm{s}$ (plus some overhead for packet headers). This is quite a lot when compared with other codecs. This codec can be used freely in VoIP applications as there are no licensing fees for it.

- Second one is G.729. It is a codec that has low bandwidth requirements but provides good audio quality $(\mathrm{MOS}=4.0)$. MOS means Mean Opinion Score. The codec encodes audio in frames, each frame is 10 milliseconds long. Given the sampling frequency of 8
$\mathrm{kHz}$, the $10 \mathrm{~ms}$ frame contains 80 audio samples. The codec algorithm encodes each frame to 10 bytes, so the resulting bitrate is $8 \mathrm{Kbit} / \mathrm{s}$ for one direction. Next one is G.723 which is a result of a competition that ITU announced with the aim to design a codec that would allow calls over 28.8 and $33 \mathrm{Kbit} / \mathrm{s}$ modem links. Because of that, we have two variants of G.723. They both operate on audio frames of 30 milliseconds (i.e. 240 samples), but the algorithms differ. The bitrate of the first variant is $6.4 \mathrm{Kbit} / \mathrm{s}$ and the second variant is $5.3 \mathrm{Kbit} / \mathrm{s}$. The encoded frames for the two variants are 24 and 20 bytes long, respectively. G.723 is a licensed codec.

Comparisons of the three codecs on various parameters are given in Table 2.

Table 2. VoIP codecs characteristics

\begin{tabular}{|c|c|c|c|c|c|}
\hline CODEC & Algorithm & $\begin{array}{c}\text { Codec } \\
\text { Delay } \\
(\mathbf{m s})\end{array}$ & $\begin{array}{c}\text { Bit } \\
\text { Rate } \\
\text { (kbps) }\end{array}$ & $\begin{array}{c}\text { Packets } \\
\text { Per } \\
\text { Second }\end{array}$ & $\begin{array}{c}\text { IP } \\
\text { Packet } \\
\text { Size } \\
\text { (bytes) }\end{array}$ \\
\hline G.711 & PCM & 0.375 & 64 & 100 & 120 \\
\hline G.729 & ACELP & 35 & 8 & 100 & 50 \\
\hline G.723 & CS-ACELP & 97.5 & 5.3 & 33 & 60 \\
\hline
\end{tabular}

\section{SIMULATION MODEL}

Simulations are performed by using OPNET Simulator version 14.5. Three designs are considered with varying subscriber stations. These designs are shown in Figure 1, 2, 3.

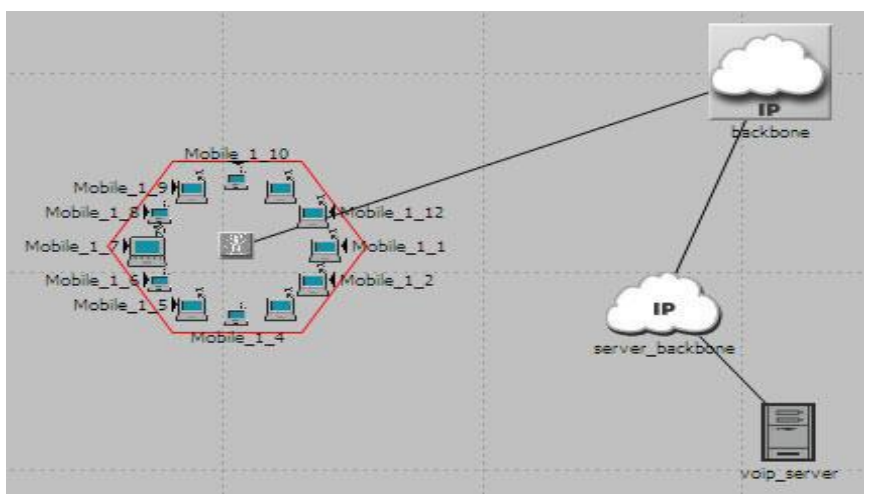

Figure 1. Design 1 with 12 Subscriber stations

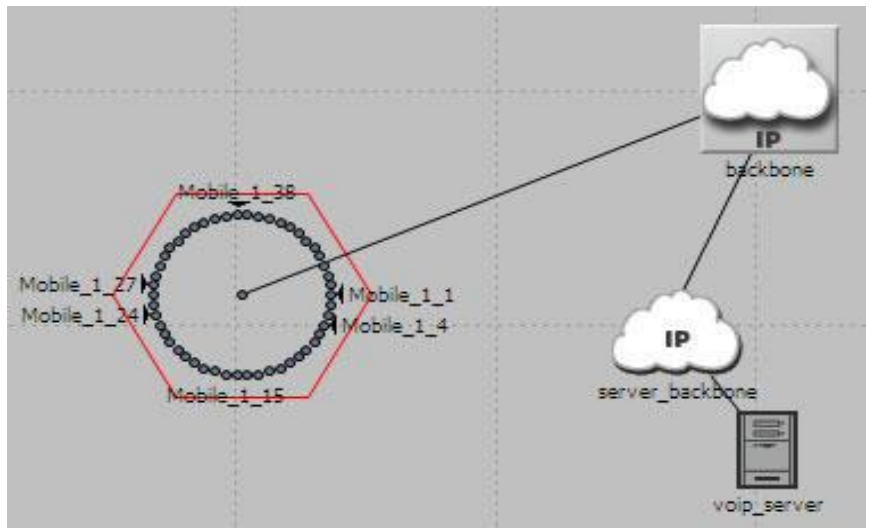

Figure 2. Design 2 with 50 Subscriber Stations 


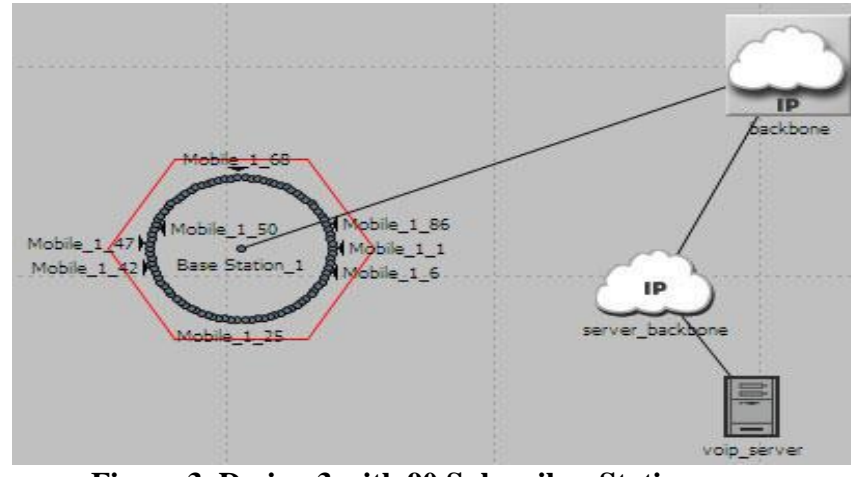

Figure 3. Design 3 with 90 Subscriber Stations

Every design consists of one cell and IP backbone, and cell radius is set to $1 \mathrm{~km}$. Subscriber node transmission power is set to $0,5 \mathrm{~W}$. base station transmission power is set to be $5 \mathrm{~W}$. The path loss and multipath model are set to free space. For the Design 1 Base station has 12 Nodes (Figure 1). Design 2 Base station with 50 nodes (Figure 2) and Design 3 Base station has 90 nodes (Figure 3).The parameter of base station and subscriber station can be seen in Table 3 and Table 4 .

Table 3. Base Station Parameters

\begin{tabular}{|c|c|}
\hline $\begin{array}{c}\text { Antenna Gain } \\
(\mathrm{dBi})\end{array}$ & $15 \mathrm{dBi}$ \\
\hline $\begin{array}{c}\text { Maximum Number } \\
\text { of SS Nodes }\end{array}$ & $\mathbf{8 / 1 6}$ \\
\hline $\begin{array}{c}\text { Channel Quality averaging } \\
\text { parameter }\end{array}$ & SISO \\
\hline $\begin{array}{c}\text { Number of Transmitters } \\
\text { Maximum Transmission } \\
\text { Power (W) }\end{array}$ & 0,2 \\
\hline Phy Profile & Wireless OFDM 20 MHz \\
\hline PHY profile Type & OFDM \\
\hline
\end{tabular}

Table 4 .Subscriber Station Parameters

\begin{tabular}{|c|c|}
\hline $\begin{array}{c}\text { Antenna Gain (dBi) } \\
\text { Power (W) }\end{array}$ & $-1 \mathrm{dBi}$ \\
\hline $\begin{array}{c}\text { Maximum Transmission } \\
\text { Phy Profile }\end{array}$ & $\begin{array}{c}\text { Wireless OFDM 20 } \\
\text { MHz }\end{array}$ \\
\hline PHY profile Type & OFDM \\
\hline $\begin{array}{c}\text { Multipath Channel } \\
\text { Model }\end{array}$ & ITU Vehicular A \\
\hline $\begin{array}{c}\text { Path loss Model } \\
\text { Terrain Type } \\
\text { (Suburban Fixed) }\end{array}$ & Free Space \\
\hline Ranging Power Step & Terrain Type A \\
\hline
\end{tabular}

\begin{tabular}{|c|c|}
\hline$(\mathrm{mW})$ & \\
\hline Contention Ranging Retries & 32 \\
\hline Piggyback BW Request & Enable \\
\hline CQICH Period & 3 \\
\hline $\begin{array}{c}\text { Contention Based } \\
\text { Reservation Timeout }\end{array}$ & 32 \\
\hline Request Retries & 32 \\
\hline $\begin{array}{c}\text { Multipath Channel } \\
\text { Model }\end{array}$ & ITU Vehicular A \\
\hline Path loss Model & Free Space \\
\hline $\begin{array}{c}\text { Terrain Type } \\
\text { (Suburban Fixed) }\end{array}$ & Terrain Type A \\
\hline $\begin{array}{c}\text { Ranging Power Step } \\
(\mathrm{mW})\end{array}$ & 0,25 \\
\hline Contention Ranging Retries & 32 \\
\hline Piggyback BW Request & Enable \\
\hline CQICH Period & 3 \\
\hline $\begin{array}{c}\text { Contention Based } \\
\text { Reservation Timeout }\end{array}$ & 32 \\
\hline Request Retries & 32 \\
\hline
\end{tabular}

\section{SIMULATION RESULTS AND ANALYSIS}

For Design 1:

Figure 4 shows comparative results of design 1 with 12 subscriber station in 1 base station. Figure 4 shows comparative result of jitter for codecs that are used in this experiment. It can be seen that the G.723 codec scheme has large value of jitter variation of $-4,70 \mathrm{E}-06$. The negative value of jitter means that the time difference between the packets at destination is less than that source. Figure 5 shows comparison for packet End to End delay. The result G.723 codec have highest voice packet delay averaging around 116,9 $\mathrm{ms}$, and the lowest voice packet is G.711 codec averaging around $76,9 \mathrm{~ms}$. In Figure 6 show comparative results for throughput of all codecs. G.711 codec has the highest throughput as a result of highest packet size with expected value 863,2 packet/sec. The G.723 codec has the lowest throughput.

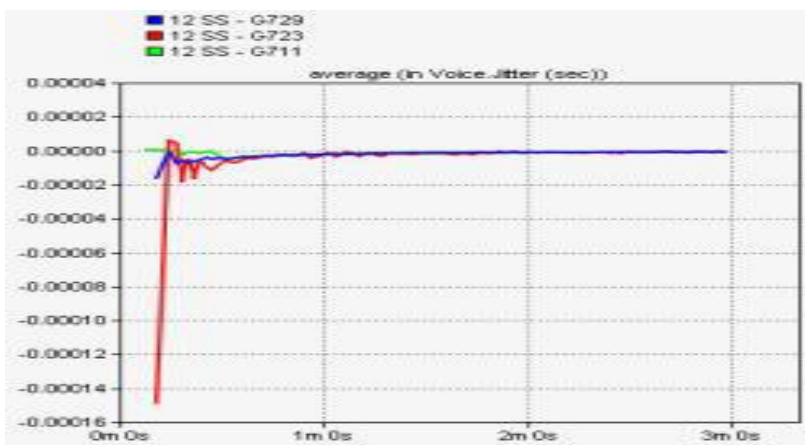

Figure 4. Results for Jitter variation for 12 Subscriber Stations 


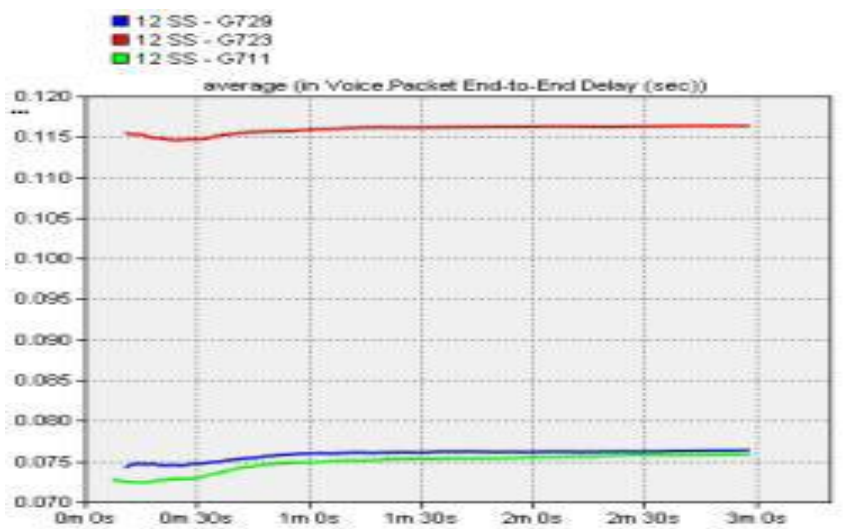

Figure 5. Results for End to End Delay for 12 Subscriber Stations

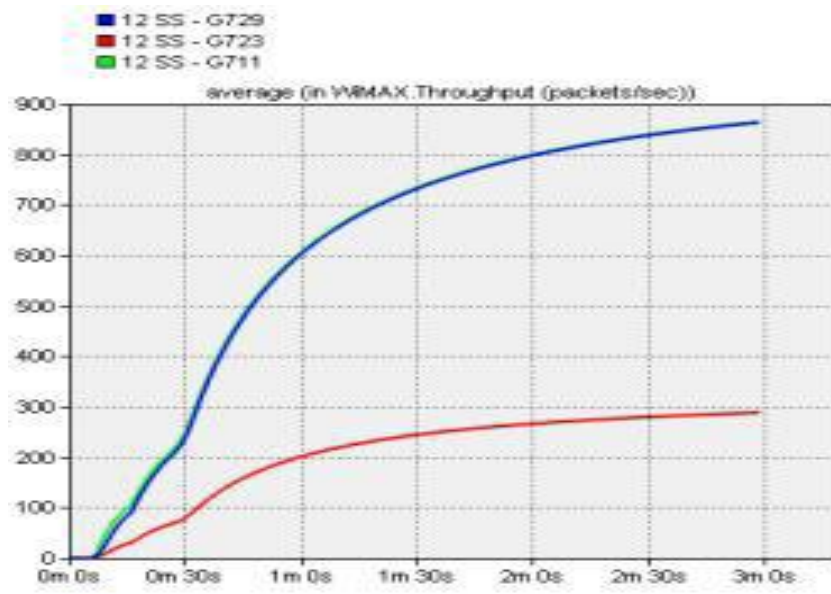

Figure 6. Results for Throughput for 12 Subscriber Stations

Comparative Results of Design 1 are given in Table 5.

Table 5 - Comparison of codecs for 12 Subscriber Stations

\begin{tabular}{|c|c|c|c|}
\hline QOS & G.729 & $\mathbf{G . 7 2 3}$ & $\mathbf{G . 7 1 1}$ \\
\hline Jitter & $-2,09 \mathrm{E}-06$ & $-4,70 \mathrm{E}-06$ & $-1,46 \mathrm{E}-06$ \\
\hline $\begin{array}{c}\text { Packet End to End } \\
\text { Delay }\end{array}$ & 0,0759 & 0,1169 & 0,0769 \\
\hline $\begin{array}{c}\text { Throughput } \\
\text { (1) }\end{array}$ & 865,1411 & 277,6556 & 863,2 \\
\hline
\end{tabular}

\section{For Design 2:}

Figure 7 shows comparative result for design 2 in the experiment with 50 subscriber station for all codecs. When 50 SS result average jitter for G. 723 bigger than others (codec), and expected value G.723 expected value -6,24E-06 sec (Figure 7). Figure 8 shows comparative packet End to End delay. It is seen from the graph that the package End to End delay is very high in the case of G.723 and the expected value of 0,1173 seconds. G.711 codec has the lowest among the three codecs with the expected value 0,0768 sec. In Figure 9 shows comparative result throughput. G.729 codec has the highest throughput as a result of highest packet size with expected value 2116,327 packet/sec.

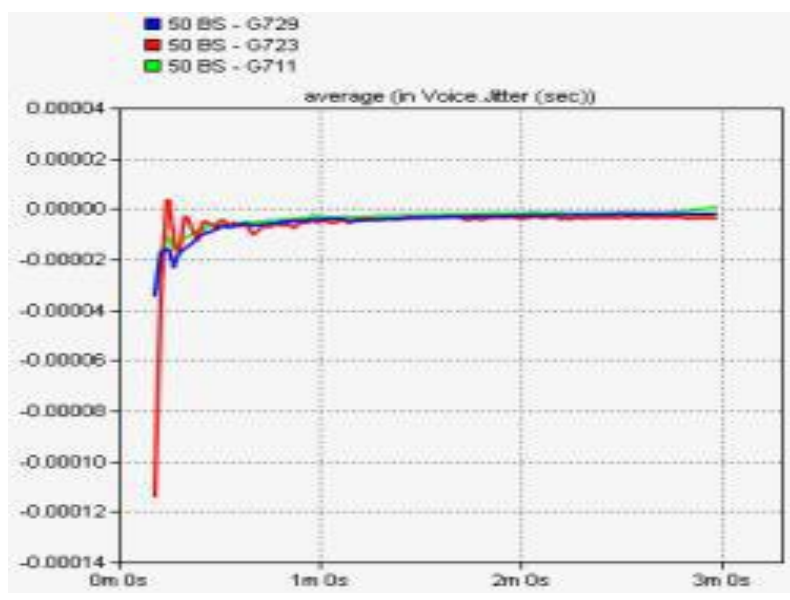

Figure 7 Results for Jitter Variations with 50 Subscriber Stations

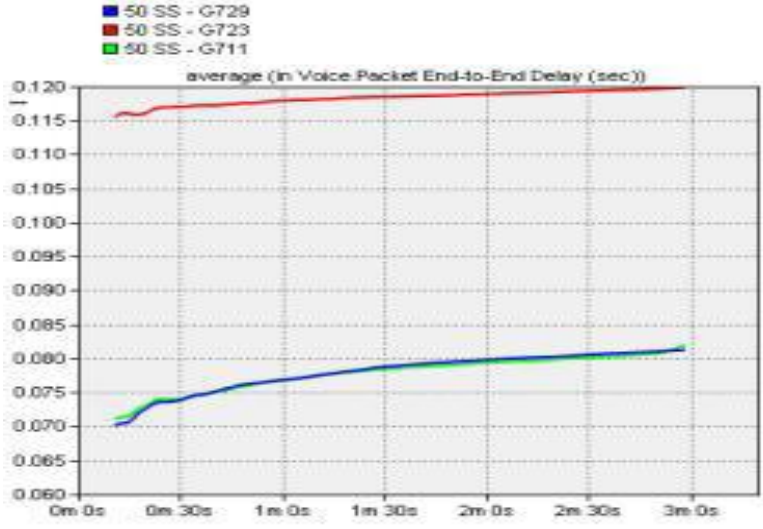

Figure 8 Results for End to End Delay with 50 Subscriber Stations

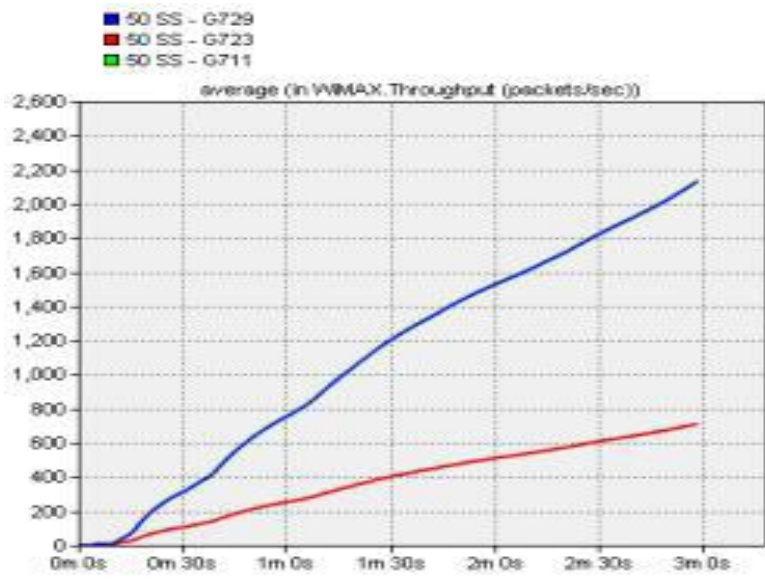

Figure 9 Results for Throughput with 50 Subscriber Stations

Comparative Results for Design 2 are shown in Table 6 
Table 6 - Comparison of Codecs for 50 Subscriber Stations

\begin{tabular}{|l|c|c|c|}
\hline QOS & G.729 & G.723 & G.711 \\
\hline Jitter & $-4,88 \mathrm{E}-06$ & $-6,24 \mathrm{E}-06$ & $\begin{array}{c}-3,58 \mathrm{E}- \\
06\end{array}$ \\
\hline $\begin{array}{c}\text { Packet End to } \\
\text { End Delay }\end{array}$ & 0,0780 & 0,1173 & 0,0768 \\
\hline Throughput & 2116,3278 & 709,8778 & 2125 \\
\hline
\end{tabular}

\section{For Design 3}

Figure 10 shows comparative results for design 3 in this experiment with 90 subscriber station. Result average jitter for G. 711 codec for this design lower than other codecs (Figure. 10). For End to End Delay in this design G.729 Codec lowest with expected value $0,082271 \mathrm{sec}$ then another codec (Figure 11) and comparison result for throughput gives G.729 codec highest with expected value 4545,1822. package/sec (Figure 12).

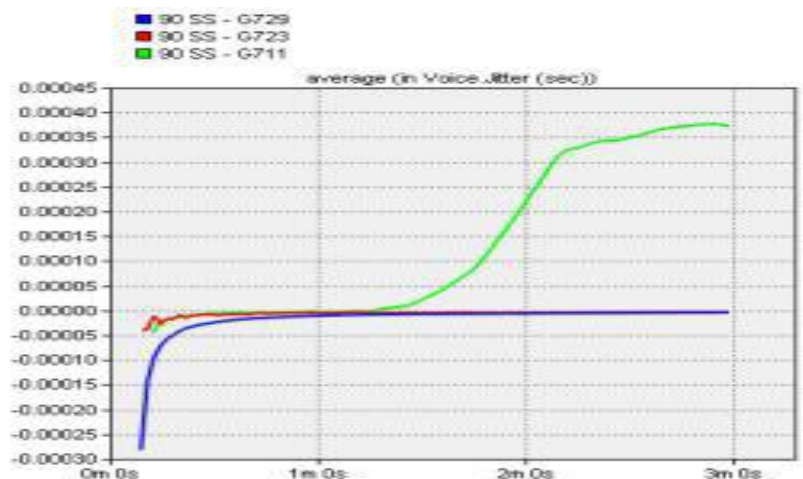

Figure 10. Results for Jitter Variations with 90 Subscriber Stations

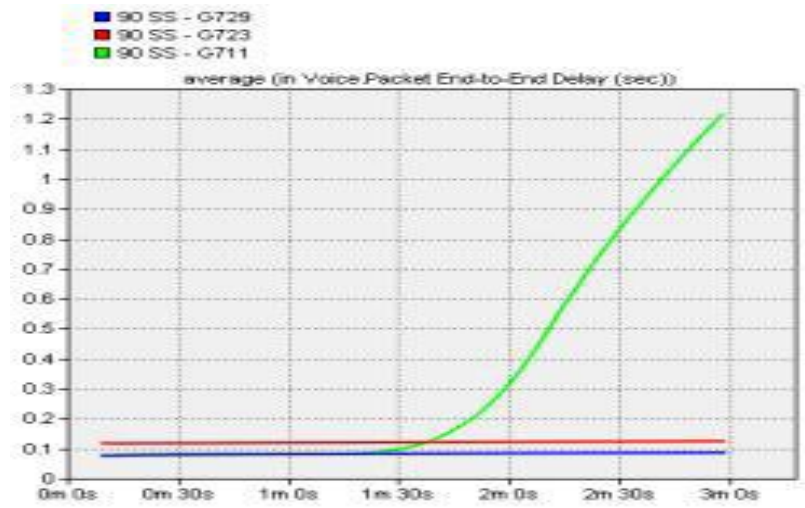

Figure 11. Results for End to End Delay with 90 Subscriber Stations

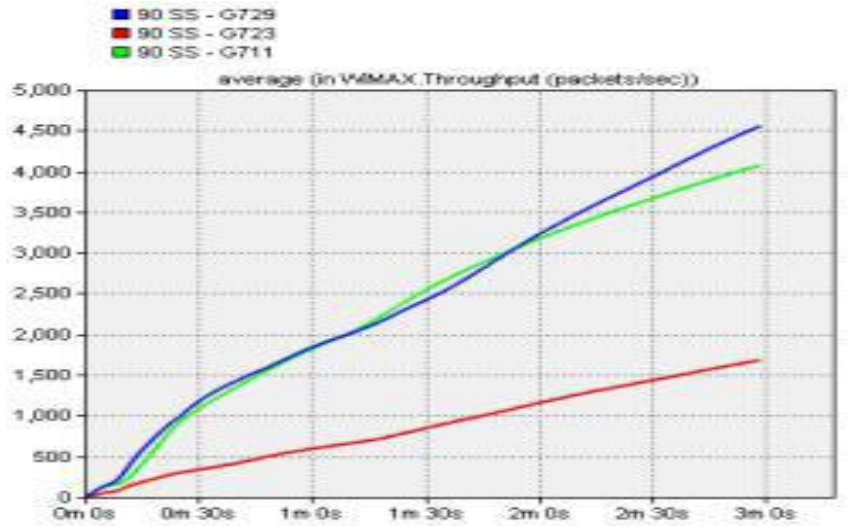

Figure 12. Results for Throughput with 90 Subscriber Stations

Comparative Results for Design 3 for various codecs are shown in Table 7.

Table 7- Comparison of Codecs for 90 Subscriber Stations

\begin{tabular}{|l|c|c|c|}
\hline QOS & G.729 & G.723 & G.711 \\
\hline Jitter & $-1,66 \mathrm{E}-05$ & $-6,39 \mathrm{E}-06$ & $1,36 \mathrm{E}-04$ \\
\hline $\begin{array}{l}\text { Packet End to } \\
\text { End Delay }\end{array}$ & 0,0823 & 0,1205 & 0,3527 \\
\hline \begin{tabular}{l} 
Throughput \\
\hline
\end{tabular} & 4545,1822 & 1672,1744 & 4065,5147 \\
\hline
\end{tabular}

\section{CONCLUSIONS}

Next Generation Networks such as WIMAX allows for more efficient bandwidth use, interference avoidance, and is intended to allow higher data rates over longer distances. Voice over Internet Protocol (VoIP) technology facilitates packet based IP networks to carry digitized voice, it uses internet protocol for transmission of voice as packets over IP networks. In this paper Simulations were conducted to evaluate performance of VOIP over NGN networks. For this purpose Simulator OPNET 14.5 have been used as the simulation platform. The parameters in this simulation which are evaluated are jitter, packet end to end delay and Throughput. Three voice codecs G.711, G.723 and G.729 are compared as the parameters of this experiment. Comparative results between the three designs in this experiment give a performance evaluation of VOIP over NGN networks. Simulation results shows that the performance of the G.711 codec is better than other codecs if seen from throughput value of which is derived. The greater the number of subscriber station, the greater the value of throughput for the G.711 codec. Thus G.711 codec can be considered as best codec. As a future work, one can take more number of QOS parameters with varying subscriber stations and simulate them to find other best possible codecs for different network applications. 


\section{REFERENCES}

[1] Y. Jung, and C. Manzano, "Burst packet loss and enhanced packet loss-based quality model for mobile voice-over Internet protocol applications," Journal of IET Communication., Vol. 8, Iss.1, pp. 41-49, 2014.

[2] T.Szigeti and C. Hattingh, "Quality of Service Design Overview”,Available:http://www.informit.com/articles/ar ticle.aspx.p=357102.

[3] Packet Loss, http.//networksolutionexperts.com/what causes-packet-loss-on-the- Internet /, Journal, Reterived.2013-11-14.

[4] Greg S. Tucker, "Voice over Internet Protocol (VoIP) and Security”, Paper in SANS Institute, October 2004.

[5] Gouda I. Salama, M. Elemam Shehab, A. A. Hafez, M. Zaki, "Performance Analysis of Transmitting Voice over Communication Links Implementing IPsec " Paper in 13th International Conference on Aerospace Sciences and Aviation Technology (ASAT), Military Technical College, Cairo, Egypt May 2009.

[6] Qinxia (Alice) He "Analyzing the Characteristics of VoIP Traffic", Thesis M.Sc., Department of Computer Science, University of Saskatchewan, Canada, July 2007.

[7] Cisco, "Enabling VoIP: Data Considerations and Evolution

ofTransmissionNetworkDesign",Available:http://www.ci sco.com/en/US/prod/collateral/optical/ps5724/ps2006/pr od_white_paper0900aecd803faf8f_ps2001_Products_Wh ite_Paper.html.

[8] K. Neupane, and et al, "Measuring the Performance of VoIP over Wireless LAN," In Proceedings of the 2011 conference on Information technology education (SIGITE '11), New York, USA, pp. 269-274, 2011.

[9] U. R. Alo, and Nweke Henry, "Investigating the Performance of VOIP over WLAN in Campus Network," Journal of Computer Engineering and Intelligent Systems, Vol.4, No.4, pp. 47-58, 2013.

[10] Webopedia, "The Difference between VoIP and PSTN Systems",Available:http://www.webopedia.com/DidYou Know/Internet/2008/VoIP_POTS_Difference_Between.a sp.

[11] Voip-Info.org, "VOIP QOS Requirements", Available: http://www.voip-info.org/wiki/ view/QOS.
[12] Goode B, "Voice over Internet Protocol (VoIP)," Proceedings of IEEE, vol. 90, no. 9, Sept. 2002, pp. 1495-1517.

[13] W. Jiang, K. Koguchi, and H. Schulzrinne, "QOS Evaluation of VoIP End-Points," Proceedings of IEEE International Conference on Communications, ICC'03, Anchorage, May 2003, pp. 1917-1921.

[14] G. Krzysztof, K. Aleksander, W. Jozef, N. Krzysztof, "Test bed analysis of video and VoIP transmission performance in IEEE $802.11 \mathrm{~b} / \mathrm{g} / \mathrm{n}$ networks," Telecommunication Systems, Springer Netherlands, vol. 48, no 3-4, pp. 247-260, December 2011.

[15] K.Salah, P. Calyam, M.I. Buhari, “Assessing Readiness of IP Networks to Support Desktop Videoconferencing using OPNET," Elsevier Journal of Network and Computer Applications (JNCA), 2006.

[16] K. Salah, A. Alkhoraidly, “An OPNET-based Simulation Approach for Deploying VoIP", Available: http://faculty.kfupm.edu.sa/ics/salah/misc/RecentPubs/IJ NM_VoIP.pdf.

[17] M. Raj, A. Narayan, S. Datta, S.K. Das, J.K. Pathak, "Fixed mobile convergence: challenges and solutions," Communications Magazine, IEEE, vol.48, no.12, pp.2634, December 2010.

[18] Hin Heng Chan, "Voice over Internet Protocol (VoIP) over 3G networks," April 2011, Available: http://www.ensc.sfu.ca/ 1jilja/ENSC427/Spring11/Projec ts/team4/ENSC427_Spring2 011_Team4_Report.pdf.

\section{AUTHOR PROFILE}

Ritesh C Sadiwala is a research scholar and is currently pursuing $\mathrm{PhD}$ in Electronics and Telecommunication Engineering from RKDF University, Bhopal INDIA. His areas of interest include VOIP Networks, Next Generation networks, Wireless Communication and communication networks.

Dr. Minal Saxena received his Ph.D. from MANIT, Bhopal, INDIA. She is currently working as a Professor and Dean (HOD) in Electronics and Communication Department in SIRT, Bhopal, INDIA. Her areas of interest are Wireless Communication, Next Generation Networks, Digital Signal Processing and Communication Networks. 